\title{
THE WORK OF THE VENEREAL DISEASES SCHEMES IN ENGLAND AND WALES IN 1936
}

In April last year, believing that a large proportion of our readers were interested in the work and results of the anti-venereal schemes in England and Wales, we reprinted in this Journal the Venereal Diseases section of the Annual Report for I935 of the Chief Medical Officer of the Ministry of Health. We think the subject is still likely to interest our readers, and below, by permission of the Controller of H.M. Stationery Office, we are republishing the corresponding section of the same report for 1936 .

Probably chief interest will be taken in the figures relating to the incidence of fresh syphilitic infections dealt with at the centres in which it is gratifying to note a further decline, to 5,675 cases, 37.6 per cent. fewer than the number in 193I. In the present report an attempt has been made to estimate the cases of early syphilis dealt with privately, and the conclusion is that the total number of cases with infections of less than one year's duration which came under medical care, privately and at the centres, in 1936 worked out at a rate of less than I.7 per I0,000 of the population. This figure may perhaps mean little to many readers until it is compared with corresponding rates in some other countries, notably Denmark and Sweden, where anti-venereal measures have been actively pursued for many years and are extensively quoted as having met with great success in respect of syphilis. In Sweden in 1935 the notified cases of primary and secondary syphilis worked out at a rate of 0.67 per I0,000 of the population. In Denmark the cases of syphilis reported officially in the same year were at the rate of $2 \cdot$ I per 10,000 , but it is admitted there that the official figures are not a reliable index of the fresh infections, and an estimate of about $\mathrm{I} \cdot 6$ per 10,000, which was based largely on cases registered at the State Serum Institute, was recently agreed by the health authorities in Denmark (private communication) to be probably more 


\section{BRITISH JOURNAL OF VENEREAL DISEASES}

accurate. In Holland a recent estimate, admittedly incomplete, which is based on a questionnaire circulated by Van Leeuwen and Hermans, make the incidence of fresh syphilis coming under medical care in r935 to be approximately $\mathrm{I} \cdot \mathrm{O}$ per I0,000. Having regard to the proportion of replies to the questionnaire, perhaps a rate of I. 4 would be closer to the truth. All these rates are regarded as very encouraging (in Denmark syphilis is regarded as a disease which is dying out). The figures contrast with estimates in U.S.A., which are startling. As a result of a number of one-day surveys conducted by the United States Public Health Service, the number of new cases of syphilis coming under medical care in that country in I935 was estimated at 5I8,000, which works out at a rate of approximately 40 per I0,000.

The Chief Medical Officer's Report contains also support for the evidence of a substantial decrease in the incidence of fresh syphilis in England and Wales in the deaths of infants certified as due to syphilis. These were 0.27 per I,000 live births in I936, a rate which was one-fifth of that in I9I2 and less than one-seventh of that in I9I7.

It may be interesting here to note that the decline in the incidence of syphilis in the civilian population is reflected in the incidence of this disease in the armed forces stationed at home. In I92I the admission rates per I,000 per annum in the three arms were: Royal Navy, 8.I ; Army, 9.8 ; and Royal Air Force, 4.I. In I935, the last year for which figures relating to incidence in all three forces are available, the rates were: Royal Navy, $3 \cdot 4$; Army, I.2 ; and Royal Air Force, 0.2.

In gonorrhœa the figures in the Chief Medical Officer's Report probably do not reflect the position in respect of incidence of the disease in the country by any means so closely as do the figures relating to syphilis. They show an increase since I920, but a decrease of approximately Io per cent. since I930. Generally speaking, the figures are not encouraging, but in this respect cannot be regarded as worse than those in Denmark and Sweden, where the notified cases in I935 worked out at rates of 27 and 17.9 respectively per 10,000 of the population. In contrast with these, the early cases dealt with at the centres in England and Wales were 8.I per I0,000. Admittedly this figure by no means accounts for all the cases coming under medical care, but it is difficult to 


\section{VENEREAL DISEASES SCHEMES}

believe that the numbers under private care exceed those dealt with at the centres so greatly as to make the true incidence greater than that in, for example, Denmark. In U.S.A. the Survey figures led to a calculation of I,037,000 fresh cases of gonorrhœa in I935. This would work out at a rate of approximately 80 per Io,ooo.

Two prime obstacles stand in the way of a reduction in the incidence of gonorrhœa in any country, viz. (a) the tendency of women with gonorrhœa to neglect to seek treatment for it; and $(b)$ the absence hitherto of any means of rendering the patient non-contagious quickly.

To the first of these attention has repeatedly been drawn in the C.M.O.'s Reports. It is shown in this Report in the ratio of females to males with gonorrhœa dealt with for the first time at the treatment centres as compared with the similar ratio in the case of syphilis. The Report shows that in syphilis the ratio was I female to 2.4 males, but in gonorrhœa it was I to 4 . The explanation of the difference in the two ratios which will probably appeal to most workers as applicable to a large proportion of the cases is that many women with gonorrhœa do not seek medical advice because in their case the signs and symptoms of the disease are trivial and are regarded by them as amongst the minor afflictions of womenkind. The remedy lies in improvements in the education of the public, leading to a greater appreciation by women of the truth that innocent-looking vaginal discharges are often gonorrhœal and ought to be examined bacteriologically.

As regards the absence of means to render the patient non-contagious quickly, perhaps in a few years commentators on the incidence of gonorrhœea will mark the year I937 as having seen, in the synthesis of one or more members of the sulphonamide group of remedies, the birth of a specific for gonorrhœa analogous to that which, by its rapid action, has helped so materially to depress the incidence of syphilis in those countries in which it has been applied without stint.

Whether or not this hope materialises it seems likely that the use of the sulphonamide group of remedies will reduce materially the work of treating gonorrhœa. It may thus affect the future planning of V.D. Treatment Centres.

The Report is as follows :

L. W. H. 